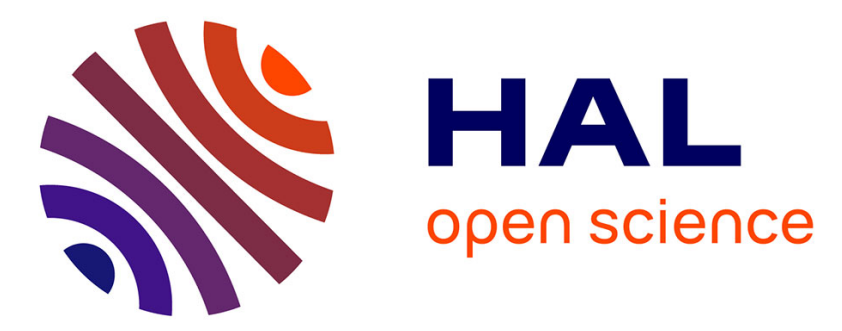

\title{
Laser-delayed double shock-wave generation in water-confinement regime
}

D Courapied, Laurent Berthe, Patrice Peyre, Frédéric Coste, J-P Zou, A.-M. Sautivet

\section{> To cite this version:}

D Courapied, Laurent Berthe, Patrice Peyre, Frédéric Coste, J-P Zou, et al.. Laser-delayed double shock-wave generation in water-confinement regime. Journal of Laser Applications, 2015, 27, pp.S29101. 10.2351/1.4906382 . hal-01300662

\section{HAL Id: hal-01300662 \\ https://hal.science/hal-01300662}

Submitted on 11 Apr 2016

HAL is a multi-disciplinary open access archive for the deposit and dissemination of scientific research documents, whether they are published or not. The documents may come from teaching and research institutions in France or abroad, or from public or private research centers.
L'archive ouverte pluridisciplinaire HAL, est destinée au dépôt et à la diffusion de documents scientifiques de niveau recherche, publiés ou non, émanant des établissements d'enseignement et de recherche français ou étrangers, des laboratoires publics ou privés. 


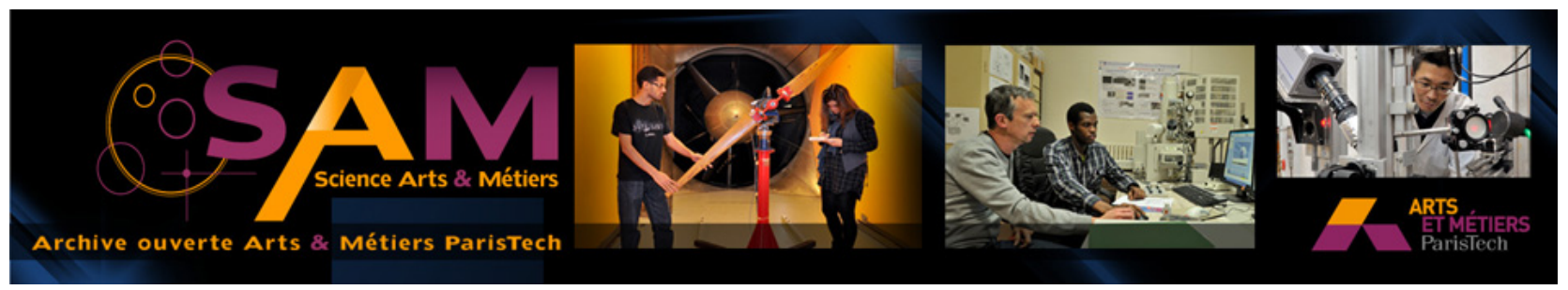

Science Arts \& Métiers (SAM)

is an open access repository that collects the work of Arts et Métiers ParisTech researchers and makes it freely available over the web where possible.

This is an author-deposited version published in: http://sam.ensam.eu Handle ID: .http://hdl.handle.net/null

\section{To cite this version :}

D COURAPIED, Laurent BERTHE, Patrice PEYRE, Frédéric COSTE, J-P ZOU, A.-M. SAUTIVET - Laser-delayed double shock-wave generation in water-confinement regime - Journal of Laser Applications - Vol. 27, p.S29101 - 2015 


\title{
Laser-delayed double shock-wave generation in water-confinement regime
}

\author{
D. Courapied, L. Berthe, P. Peyre, and F. Coste \\ Processes and Engineering in Mechanics and Materials Laboratory (PIMM), CNRS-ENSAM Paristech, \\ 151 Bd de I' Hôpital, 75013 Paris, France \\ J.-P. Zou and A.-M. Sautivet \\ Laboratoire pour I' utilisation des lasers intenses (LULI), Ecole Polytechnique, 91128 Palaiseau Cedex, \\ France
}

\begin{abstract}
This paper investigates the different physical processes involved during laser-delayed double shockwave generation in water-confined geometry. With this technique, two laser pulses, separated by a $\Delta \mathrm{t}$ duration, irradiate a target immersed in water at an intensity of a few $\mathrm{GW} / \mathrm{cm}^{2}$ and form a high pressure plasma which results in a double shock-wave generation. This 2 pulses configuration is currently being investigated as an attractive method for improving the LASer Adhesion Test (LASAT) [L. M. Barker and R. E. Hollenbach, J. Appl. Phys. 43, 4669-4674 (1972)] technique by adapting the time delay $\Delta \mathrm{t}$ to the position of interfaces. The LASAT technique is a noncontact adhesion test allowing to generate a high-level tensile stress near interfaces with the use of laser-driven shock wave. The generation of two delayed high-intensity shock waves by laser plasma in the water-confinement regime has been investigated at 10ns@532nm with the new Nd:YAG laser GAIA from Thales Laser company in the new facility HEPHAISTOS. For each incident Gaussian laser impulsion, the characterization of the high-amplitude laser-plasma-generated shock wave and its propagation through the target has been performed using a velocity interferometer system for any reflector [L. Berthe et al., "State-of-the-art laser adhesion test (LASAT)," Nondestr. Test. Eval. 26(3-4), 303-317 (2011)]. The new laser facility allows us a nanosecond-control of the time delay between the two laser pulses and a precise control of each laser maximum-intensity. Therefore, the influence of the first laser-induced plasma, on the second shock-wave generation has been studied by modifying different parameters such as the delay $\Delta \mathrm{t}$ and the intensity I1 and 12 of each pulse and different aluminum plate thicknesses from 0.2 to $1.5 \mathrm{~mm}$. Preliminary tests show that the maximum pressure level of the second generated shock wave is sensitive to the time delay between the two impulsions and influenced by the plasma generated by the first laser pulse.
\end{abstract}

Key words: laser-matter interaction, shock-wave, water confinement regime

\section{INTRODUCTION}

The LASer Adhesion Test (LASAT) technique is a laser adhesion test allowing the generation of high tensile stresses in materials introduced by Vossen in the 1970 s. ${ }^{1,2}$ To produce a laser-generated shock-wave in a target, a high power laser irradiation is used. When the laser irradiation is focused on the target, the laser-matter interaction leads to an intense plasma formation. ${ }^{3-8}$ As a response to the plasma expansion, a shock wave is generated through the target and propagates. The characteristic of the shock wave depends on several parameters, impulsion shape and duration, energy, wavelength. To improve the pressure load in the target, a water confinement is used as shown in Fig. 1.

This confinement consists in the addition of a water layer above the target. This additional water layer constrains the plasma expansion and allows the generation of 5-10 times higher pressure loads ${ }^{5-8}$ than in direct regime. When the shock wave reaches the back face, it is reflected as a release wave. In the same time, a release wave also propagates in the sample because of the end of the pressure load.
When these two releases waves intersect, high tensile stresses are generated. However, the location of the tensile stresses is dependent of the impulsion profile and mechanical properties (Fig. 1).

This technique is well efficient to determine interface strengths. Indeed, if the location of the tensile stresses is

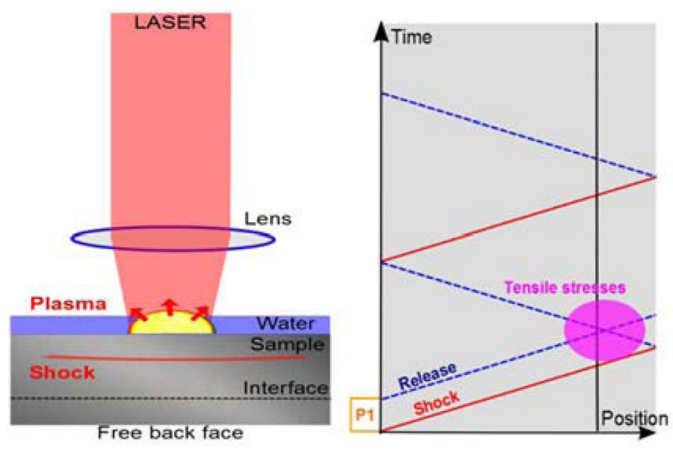

FIG. 1. Left-Sketch of the laser shock formation by interaction with a target. Right-Time/position diagram showing shock-wave propagation in a target. 
close to an interface, the local tensile stress generated in the material could result in the debonding of the interface. ${ }^{9-13}$ The paper presents here below a new approach in order to improve the technique and control the location of the tensile stresses.

\section{DESCRIPTION OF THE DOUBLE SHOCK ON THE FRONT FACE TECHNIQUE}

To improve the LASAT technique, some possibilities have emerged. ${ }^{14}$ One technique is using a double shock on the assembly front face. This solution consists in the use of two delayed Gaussians laser pulses. The idea is to precisely localize the tensile zone enhancing the main tensile level generated by the first laser pulse, reflected on the back face, by the one created by the second one. This fully original configuration is allowed by HEPHAISTOS facility allowing a nanosecond control of the time delay between two laser pulses. Figure 2 shows an example of the double pulse loading applied on the front face, on a time/space diagram. Whereas the classical LASAT technique generates a tensile zone near the back surface (zone 1), the new technique generates the tensile zone deeper in the target (zone 2).

To master the technique, a better understanding of the generation of time-delayed double shock wave applied on the front face of materials is required.

\section{DESCRIPTION OF THE DOUBLE SHOCK-WAVE GENERATION TECHNIQUE}

The laser-delayed double shock-wave generation in water-confinement regime uses two time-delayed laser pulses. The two impulsions applied on the front face of the target generate two time-delayed shock waves propagating in the target. While the first shock wave is generated through the classical plasma processes widely described before, the physical processes involved in the second one are more complicated. Indeed, the plasma created during the crossing of the water-confinement layer by the first impulsion may affect the propagation of the second pulse (Fig. 3). Thus, some

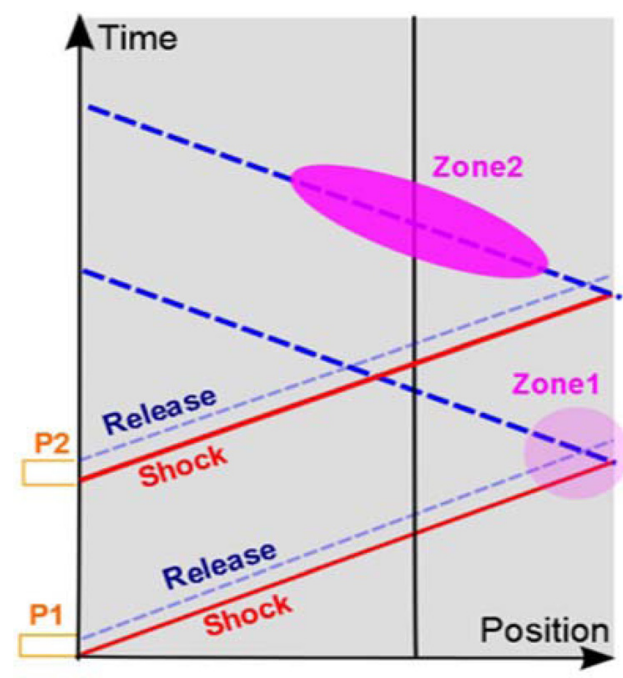

FIG. 2. Time/position diagram showing the propagation of the two shock waves in the double front face configuration.

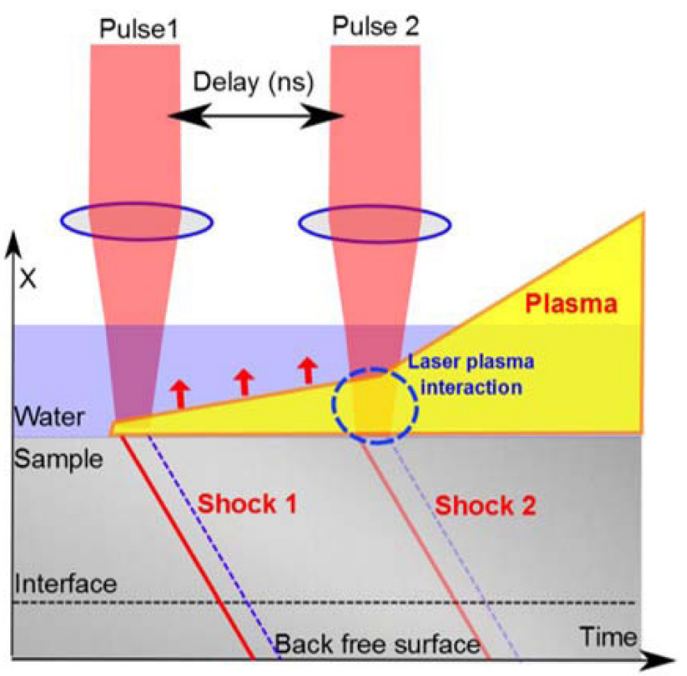

FIG. 3. Sketch of the double laser shock formation by interaction with a target.

parameters like the first impulsion intensity and delay between the two impulsions are expected to influence the second pressure load. This paper presents some pressure determination in such configuration.

\section{EXPERIMENTAL PROCEDURE}

\section{A. Laser source}

The laser source used to perform the experiments belongs to the HEPHAISTOS laser facility of PIMM, Paris. This new laser is a 10ns@532nm Nd:YAG laser GAIA from Thales Laser company. It has two separated polarized (S and P) beams named beam called A and beam B, respectively. Moreover, a nanosecond-control delay between the two beams could be imposed allowing the generation of two delayed Gaussian impulsions (Fig. 4). It is also possible to control the intensity of each pulse but not the pulse duration that remains equal to $10 \mathrm{~ns}$.

\section{B. Diagnostic}

The main diagnostic used during these experiments is a VISAR (velocity interferometer system for any reflector). ${ }^{15}$

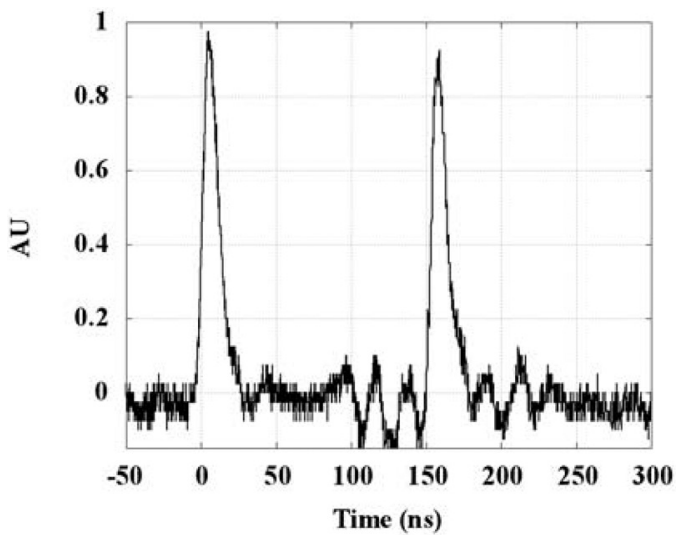

FIG. 4. Photodiode signal of two near Gaussian impulsions delayed by $150 \mathrm{~ns}$. 
The VISAR technique measures the back free velocity of the target during the propagation of the two shock waves. For a one pulse-laser impact, the time profile of the back face velocity (Fig. 5) gives information on the pressure load.

The back free surface velocity is also quite interesting for high strain rate spallation and dynamic damage investigations. ${ }^{16,17}$

\section{Materials}

The samples are made of pure aluminum from Goodfellow company. Different thicknesses are used. The $1.5 \mathrm{~mm}$-thick aluminum foils are used to characterize the pressure load profile induced by a single pulse under waterconfinement regime. Indeed, the back and forth of the shock wave in the $1.5 \mathrm{~mm}$-thick aluminum takes more time than in the $1 \mathrm{~mm}$-thick ones. Thus, it is possible to better simulate the release of the shock wave. The $1 \mathrm{~mm}$ ones are used to perform the experiments on the double shock-wave generation because the back and forth of the shock wave is greater than the time delay and the attenuation is weaker for the $1.0 \mathrm{~mm}$ thick plate. The $0.2 \mathrm{~mm}$-thick foils are mostly used to obtain the pressure-flux curve to minimize shock-wave attenuation. In the following, the results obtained on $1 \mathrm{~mm}$ thick samples are discussed.

\section{Numerical simulation of shock-wave generation}

The numerical simulations have been performed with ESTHER code developed in the CEA. ESTHER is an ID Lagrangian code allowing the study of the laser-matter interaction through the evolution of various materials stack evolving from solid phase to plasma phase under intense radiation (laser, X-ray electrons, ions, and neutrons). The state equation for the aluminum is a multiphase BLF (Bushman, Lomonosov, and Fortov) one and an elastic plastic model is used. The code is not used to simulate the lasermatter interaction yet. Thus, the initial pressure on the front face of the sample is set by a pressure load profile. However, some works already exist to simulate the behavior of the plasma during the laser-matter interaction. ${ }^{18-21}$

The numerical simulations of back free surface velocity profiles are done by simulating a pressure profile on the front face of the sample. The simulation results are compared to

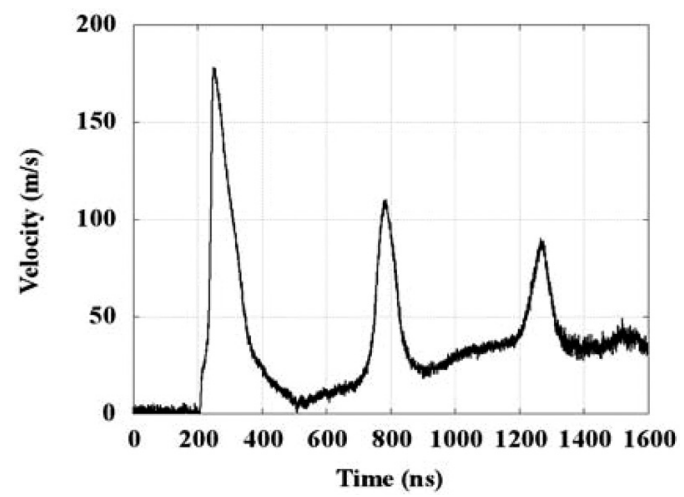

FIG. 5. Back free surface velocity of a $1.5 \mathrm{~mm}$ thick aluminum sample at $3.3 \mathrm{GW} / \mathrm{cm}^{1}$ for one Gaussian pulse.

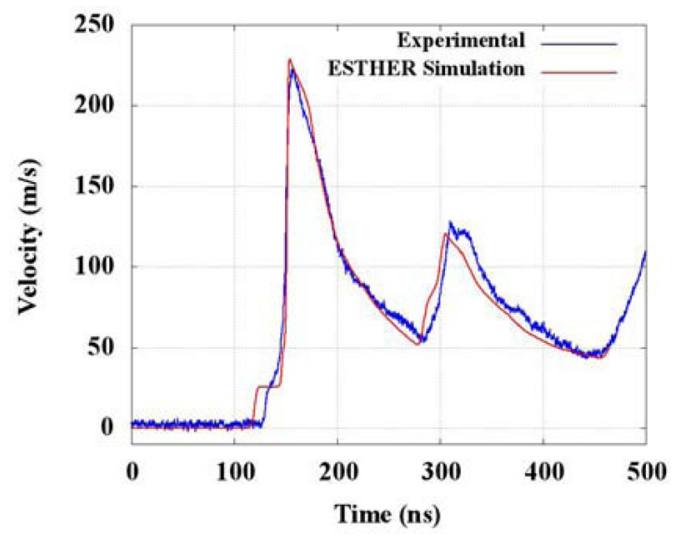

FIG. 6. Comparison of experimental and numerical signal of the back face velocity signal of a $1.0 \mathrm{~mm}$ thick aluminum at $3.5 \mathrm{GW} / \mathrm{cm}^{2}$ for the two beams with a delay of $150 \mathrm{~ns}$.

the experimental back free surface velocity signals obtained with the VISAR. When the calculated velocity signal fits the experimental one, the profile of ablation pressure is saved and considered as the pressure profile generated during the experiments.

Figure 6 shows an example of experimental back free surface velocity compared to the corresponding ESHER simulation and Fig. 7 shows the corresponding pressure profile. In that case, the $3.5 \mathrm{GW} / \mathrm{cm}^{2}$ induces a nearly $4 \mathrm{GPa}$ maximum pressure value that accelerates the $1.0 \mathrm{~mm}$ thick foil up to a $225 \mathrm{~m} / \mathrm{s}$ maximum velocity. The value of $3.5 \mathrm{GW} / \mathrm{cm}^{2}$ is chosen to avoid the breakdown plasma effects at the surface of the confining water.

\section{EXPERIMENTAL RESULT}

\section{A. Influence of the time delay $\Delta t$ between the two pulses}

First, this paper discusses the influence of the time delay $\Delta t$ between the two incident laser pulses, and between the resulting pressure loadings. The delay is limited from 0 to $250 \mathrm{~ns}$ to avoid the superimposition of the back and forth of the first pulse and the second shock wave. In those configurations, the velocity signal of the second impulsion is not perturbed by the return of the first one.

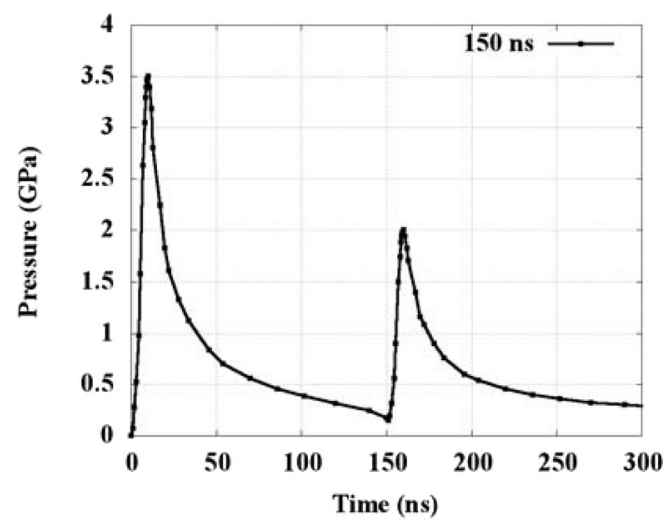

FIG. 7. Pressure profile for $2 \times 3.5 \mathrm{GW} / \mathrm{cm}^{2}$ previous simulation for a delay of $150 \mathrm{~ns}$. 


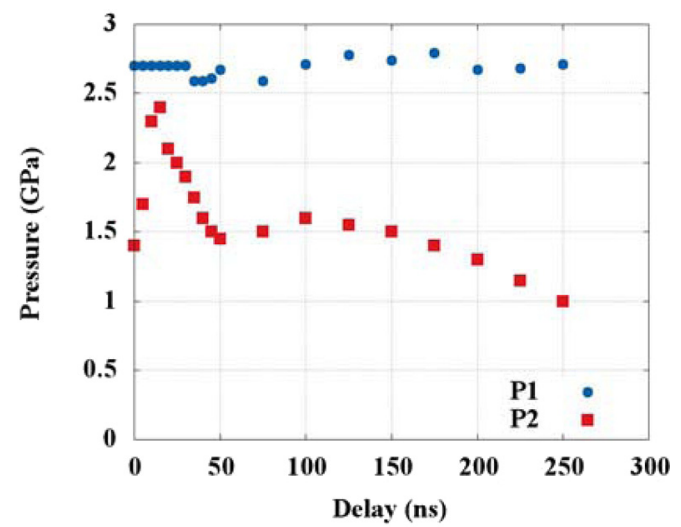

FIG. 8. Effect of the variation of the delay $\Delta \mathrm{t}$ on the pressures PI and P2 at $2.5 \mathrm{GW} / \mathrm{cm}^{2}$ for each impulsion.

Figure 8 shows a comparison between the pressure PI generated by the first pulse and $\mathrm{P} 2$ generated by the second one as a function of the delay between the two laser pulses. PI and P2 are estimated by simulations fitting the velocity signals.

First of all, the pressure PI does not change $(\simeq 2.7 \mathrm{GPa})$ with the delay. There is obviously no influence of the second impulsion on the first one. However, the pressure P2 induced by the second pulse is shown to be dependent on the delay $\Delta$ t. From Fig. 8, it seems that three zones can be distinguished: (1) between 0 and $15 \mathrm{~ns}, \mathrm{P} 2$ increases with the delay from 1.4 to $2.4 \mathrm{GPa}$, (2) between 15 and $50 \mathrm{~ns}$, a sharp pressure decrease is shown with the delay down to $1.5 \mathrm{GPa}$, (3) above $\mathrm{At}=50 \mathrm{~ns}, \mathrm{P} 2$ is constant to $1.5 \mathrm{GPa}$, then decreases to $1 \mathrm{GPa}$ at $250 \mathrm{~ns}$.

\section{B. Influence of the intensity of the first pulse}

The paper addresses here the influence of the intensity $\left(\mathrm{GW} / \mathrm{cm}^{2}\right)$ of the first pulse versus pressure generation. Experiments have been made by step-by-step decreasing the intensity of the first pulse by $10 \%$ between each experiment. Two different time delays have also been tested, 50 and $150 \mathrm{~ns}$. Figure 9 represents the variation of the pressure values PI and P2 as a function of the intensity of the first pulse for the two different delays considered.

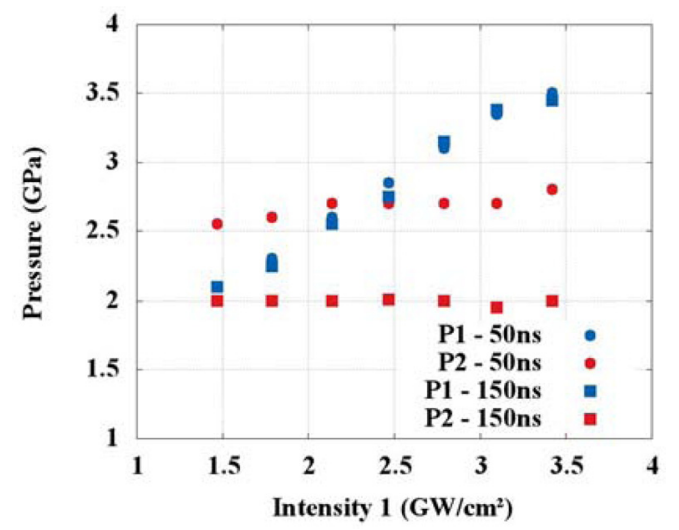

FIG. 9. Effect of the variation of the intensity of the first pulse on the pressures PI and P2. The intensity of the second pulse is kept constant at $3.5 \mathrm{GW} / \mathrm{cm}^{2}$.

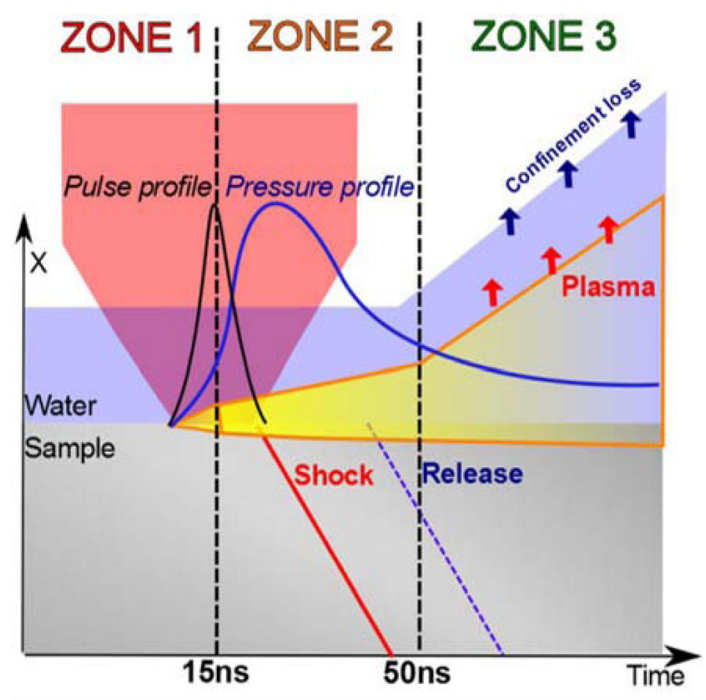

FIG. 10. Scheme of the laser-matter interaction for one Gaussian pulses.

Figure 9 reveals that when the intensity of the first pulse logically decreases, the pressure PI also decreases according to the pressure-flux curve. The pressure of the second shock wave seems to be rather constant whatever the first pulse intensity value. Moreover, the pressure P2 at $50 \mathrm{~ns}(\simeq 2.0 \mathrm{GPa})$ is lower than the pressure P2 at $150 \mathrm{~ns}(\simeq 2.7 \mathrm{GPa})$, which result seems apparently contradictory with Fig. 8 where P2 values are similar for $\Delta \mathrm{t}=50 \mathrm{~ns}$ and $\Delta \mathrm{t}=150 \mathrm{~ns}$.

\section{DISCUSSIONS}

Coming back to the results presented in Fig. 8, the pressuredelay curve could be separated in three time zones (Fig. 10):

The first one, "plasma formation (0-15 ns)," where the laser-matter interaction due to the first impulsion heats the surface of the sample and generates a plasma. In this zone, the plasma absorption increases the laser-matter interaction for the second impulsion and increases the value of P2. However, in this zone, the two generated shock waves are

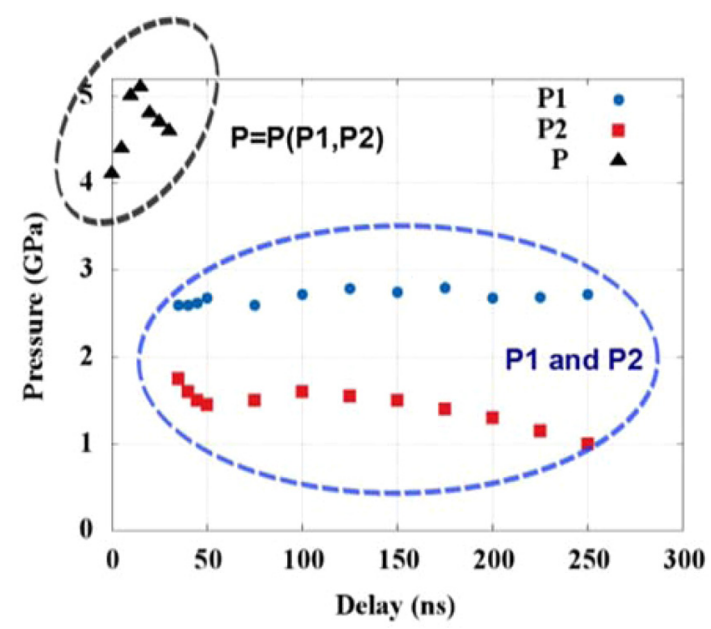

FIG. 11. Highlight of the two or three delay times zones where the two pressure loads are superimposed (green) and separated (blue). 


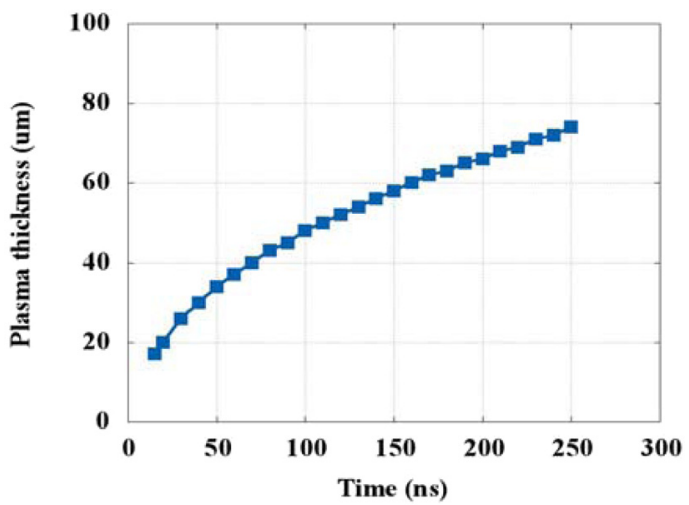

FIG. 12. Plasma thickness vs time for an $2.5 \mathrm{GW} / \mathrm{cm}^{2}$ laser impulsion on aluminum in-water confinement regime.

superimposed so it is incorrect to dissociated P2 from P1. Consequently, the generated pressure load is $\mathrm{P}=\mathrm{P}(\mathrm{P} 1, \mathrm{P} 2)$ and the pressure load duration is also increased (Fig. 11).

The second one is the "plasma screening (15-50 ns)" zone. After $50 \mathrm{~ns}$, most of the energy is deposited on the material. In this configuration, the thickness of the plasma is not negligible anymore and the second impulsion starts being absorbed by the plasma, thus generating a pressure decay. The plasma thickness could be calculated using the extended model developed by Devaux ${ }^{22}$ (Fig. 12).

The last zone $(\Delta \mathrm{t}>50 \mathrm{~ns})$ is the "plasma expansion and loss of confinement" zone. After the first impulsion (up to $50 \mathrm{~ns}$ ), the plasma expansion minimizes its absorption and allows the second impulsion reaching the surface. Simultaneously, the progressive loss of confinement reduces the pressure.

Finally, experiments carried out on the delay variation at $2.5 \mathrm{GW} / \mathrm{cm}^{2}$ show that, from $50 \mathrm{~ns}$ delay, the pressure $\mathrm{P} 2$ of the second shock wave decreases with the delay $\Delta \mathrm{t}$. However, under $50 \mathrm{~ns}$, the plasma effects are complicated and more experiments have to be done to better understand the phenomena involved. Nevertheless, Fig. 9 shows that more than $50 \mathrm{~ns}$ the behavior of the laser-matter interaction is quite predictable. The main interest of this phenomenon is that it is possible to adjust the values of the shock amplitudes generated in the sample.

Coming back to the results presented in Fig. 9, it was already said that the decrease of the intensity of the first pulse decreases the value of the pressure PL. However, the loss of pressure P2 between the two time delays (50 and 150 ns) shows that the delay between the two impulsions affects the second pressure load. Moreover, the intensity of the second impulsion also has an influence on the results between the two delays (Table I).

TABLE I. Summary of some values of P2 for two different intensities and two different delays.

\begin{tabular}{lccc}
\hline \hline & $\Delta \mathrm{t}=50 \mathrm{~ns}$ & $\Delta \mathrm{t}=150 \mathrm{~ns}$ & Ratio \\
\hline $\mathrm{I} 2=2.5 \mathrm{GW} / \mathrm{cm}^{2}$ & $1.45 \mathrm{GPa}$ & $1.50 \mathrm{GPa}$ & $+3.4 \%$ \\
$\mathrm{I} 2=3.5 \mathrm{GW} / \mathrm{cm}^{2}$ & $2.7 \mathrm{GPa}$ & $2.0 \mathrm{GPa}$ & $-20 \%$ \\
\hline \hline
\end{tabular}

\section{CONCLUSION}

To conclude, even if the classical LASAT technique is already and will remain an efficient technique to test the strength of interfaces, the double shock-wave technique seems to be a good way of improvement. However, our preliminary experiments show that some work has still to be done to better understand the laser-plasma interaction occurring for the second pulse. Nevertheless, for delays up to $50 \mathrm{~ns}$, the pressure values of the two shock waves generated in the sample could be clearly identified with VISAR diagnostic and associated simulations. A good way of improvement also will be to better simulate the laser-matter interaction with the ESTHER code in order to understand the plasma behavior during the first $50 \mathrm{~ns}$ after the first impulsion. This work is so the first step to master the double shock bond test applied on the front face of targets.

\section{ACKNOWLEDGMENTS}

The authors would like to thank the French National Research Agency, for supporting the ARCOLE project, and the SESAME from the "île de France" region.

${ }^{1}$ L. Berthe, M. Arrigoni, M. Boustie, J. P. Cuq-Lelandais, C. Broussillou, G. Fabre, M. Jeandin, V. Guipont, and M. Nivard, "State-of-the-art laser adhesion test (LASAT)," Nondestr. Test. Eval. 26(3-4), 303-317 (2011).

${ }^{2}$ A. W. Stephens and J. L. Vossen, "Abstract: Measurement of interfacial bond strength by laser spallation,” J. Vac. Sci. Technol. 13, 38 (1976).

${ }^{3}$ N. C. Anderholm, "Laser-generated stress waves," Appl. Phys. Lett. 16, 113 (1970).

${ }^{4}$ J. A. Fox, "Effect of water and paint coatings on laser-irradiated targets," Appl. Phys. Lett. 24(10) 461-464 (1974).

${ }^{5}$ R. Fabbro, J. Fournier, P. Ballard, D. Devaux, and J. Virmont, "Physical study of laser produced plasma in confined geometry," J. Appl. Phys. 68, 775-784 (1990).

${ }^{6}$ L. Berthe, R. Fabbro, P. Peyre, L. Tollier, and E. Bartnicki, "Shock waves from a water confined laser-generated plasma," J. Appl. Phys. 82(6), 2826-2832 (1997).

${ }^{7}$ L. Berthe, "Processus de claquage de millieux transparents sous irradiation laser," Application au choc laser en régime de confinement par eau, Thèse de l'unviversité Paris XI, 1998.

${ }^{8}$ A. Sollier, "Etude des plasmas générés par interaction laser-matiére en regimé confine," Application au traitement des matériaux par choc laser, Thèse de l'université de Versailles Saint-Quentin en Yveline, 2002.

${ }^{9} \mathrm{C}$. Bolis, "Etude numérique et expérimentale de la séparation par chocs brefs d'interface et de revêtement multi-couches," Application au test d'adhérence par choc laser, These de l'université de Poitiers, Ecole doctorale sciences pour l'ingénieur, 2004.

${ }^{10} \mathrm{M}$. Arrigoni, "Etude de 1 'influence de rugosités d'interface, de porosités, et de l'épaisseur d'échantillon sur la propagation des chocs dans des systémes revetus," Application au precede LASAT, Thèse de l'université de Poitiers, Ecole doctorale sciences pour l'ingénieur, 2004.

${ }^{11}$ S. Barradas, R. Molins, M. Jeandin, M. Arrigoni, M. Boustie, C. Bolis, L. Berthe, and M. Ducos, "Application of laser shock adhesion testing to the study of the interlamellar strength and coating-substrate adhesion in cold-sprayed copper coating of aluminum," Surf. Coat. Technol. 197, 18-27 (2005).

${ }^{12}$ C. Bolis, L. Berthe, M. Boustie, M. Arrigoni, S. Barradas, and M. Jeandin, "Physical approach of adhesion test using laser driven shock wave," J. Phys. D 40(10), 3155-3163 (2007).

${ }^{13}$ M. Arrigoni, S. Barradas, M. Braccini, M. Dupeux, M. Jeandin, M. Boustie, C. Bolis, and L. Berthe, "A comparative study of three adhesion test (EN 582, similar to ASTM C633, LASAT, and bulge and blister test performed on plasma sprayed copper deposited on aluminum 2017 subtrates," J. Adhes. Sci. Technol. 20(5), 471-487 (2006).

${ }^{14} \mathrm{R}$. Ecault, "Experimental and numerical investigations on the dynamic behavior of aeronautic composites under laser shock-Optimization of a shock wave adhesion test for bonded composites," Thèse de l'Ecole Nationale Superieure de Mecanique er d'Aerotechnique, 2013. 
${ }^{15}$ L. M. Barker and R. E. Hollenbach, "Laser interferometer for measuring high velocities of any reflecting surface,” J. Appl. Phys. 43, 4669-4674 (1972).

${ }^{16}$ L. Tollier, R. Fabbro, and E. Bartnicki, "Study of laser-driven spallation process by VISAR interferometry technique. I. Laser chock characterization," J. Appl. Phys. 83(3), 1224-1230 (1998).

${ }^{17}$ L. Tollier, R. Fabbro, and E. Bartnicki, "Study of laser-driven spallation process by VISAR interferometry technique. II. Experiment and simulation of the spallation process," J. Appl. Phys. 83(3), 1231-1237 (1998).

${ }^{18} \mathrm{~B}$. Wu and Y. C. Shin, "A self-closed thermal model for laser shock peening under the water confinement regime configuration and comparisons to experiments,” J. Appl. Phys. 97, 113517 (2005).
${ }^{19}$ B. Wu and Y. C. Shin, "A one-dimensional hydrodynamic model for pressures induced near the coating-water interface during laser shock peening,' J. Appl. Phys. 101, 023510 (2007).

${ }^{20} \mathrm{~B}$. Wu and Y. C. Shin, "Two dimensional hydrodynamic simulation of high pressures induced by high power nanosecond laser-matter interactions under water," J. Appl. Phys. 101, 103514 (2007).

${ }^{21} \mathrm{~B}$. Wu and Y. C. Shin, "Laser pulse transmission through the water breakdown plasma in laser shock peening," Appl. Phys. Lett. 88, 041116 (2006).

${ }^{22}$ D. Devaux, "Caractérisation des plasmas formés par laser impulsionnel en géométrie confine," Application au choc laser, Thèse de l'Université Paris XI Orsay, 1993. 